\title{
Investment Attitude of Working Women: A Study of Education Sector in Punjab
}

\author{
Poonam Sharma*, Navdeep Kaur \\ P.G. Department of Commerce \& Business Administration, Khalsa College Amritsar -143005, Punjab, India
}

E-mail: drps1102@gmail.com*,ndeep1930@gmail.com

\section{ARTICLE INFORMATION}

Received: May 5, 2019

Revised: June 25, 2019

Accepted: June 29, 2019

Published online: October 25, 2019

Keywords:

Investment, Women investors, Education sector, Factor analysis

DOI: $10.15415 /$ jtmge.2019.102007

\begin{abstract}
Investment is important for improving productivity and increasing the competitiveness of an economy. The present paper is an attempt to explore the factors influencing the investment attitude of women working in the education sector (covering the Government, Semi Government and Private domain) in the Punjab State in India. Even though, general profile of women investors is changing in tune with time, but they are insulating in various spheres of investment such as awareness and preference of investment. Today, the role of women has changed from "Savers to Investors". Factor analytical results revealed that women investors prefer to invest in risk free securities. The level of financial knowledge also influences their investment attitude. The present study reveals the factors namely, secure investment avenues, financial literacy, stock market investment and post office schemes, bank deposits, physical assets, risk taking ability and concern for financial matters that are important to women working in education sector.
\end{abstract}

\section{Introduction}

The investment decision of individual depends upon their financial literacy and awareness about various investment outlets. "There are many determinants of financial literacy level which influences how an individual deals with the routine money matters and financial transactions. These determinants include socio-demographic factors like education, income level, marital status, domicile, gender, family income and behavior, exposure to outside world, retirement needs, awareness about financial instruments etc."(Arora, A., 2016). Even though, general profile of women investors is changing in tune with time. But they are insulating in various spheres of investment such as awareness, preference of investment (Kousalya and P. Gurusamy, 2012).

Empowerment of women in the economic and social fields constitutes one of the fundamental objectives of all development efforts in the region" (Mishra, B. and Kar, N., 2004). But today the role of women has changed from "Savers to Investors". Employed women have a greater propensity to save and invest because of their independent earning power (Lad and Pawar, 2015). Women in India now participate in all activities such as education, politics, media, art \& culture, service sectors, defence to driving etc. Women as investors start moving beyond the traditional investment options of Fixed Deposits,
Post Office Saving Schemes, Saving Deposits in bank to sophisticated investment options in the form of Bonds, Mutual Funds, Real Estate and even Equity shares. In this light, the present study is an attempt to explore the factors influencing the investment attitude of women working in the education sector (covering the Government, Semi Government and Private domain) in Punjab state in India.

\section{Review of Literature}

The area of factors influencing the investment attitude of women has been discussed and analyzed by various researchers and academicians from time to time. Bernasek and Bajtelsmit (2002) explored the factors that increase women's participation in household saving and investment decision. The data was collected from Spring 2000 survey of university faculty employed at five Colorado Universities. Respondents completed a detailed and comprehensive questionnaire on the household's financial position, the financial decision making process within the household, attitude towards financial risk of household members and demographic characteristics of the household. Mishra and Kar (2004) examined the family or group influence on the investment decision of employed women, the degree of awareness of investment instruments, associated intricacies, also identified the factors influencing employed women investment decisions 
besides assessing the extent of stock market investment or investment in risky instruments by employed women. The statistical tools used for analyzing data was Simple percentage, Chi-square analysis, Garret ranking and factor analysis. It was observed that desire for investment in gold was more or less same irrespective of qualification of the respondents. Janice and Maire Dwyer (2007) overviewed the factors that were likely to influence saving and investment attitudes and behavior in New Zealand. The information was collected through a review of policy settings and published studies on savings, interviews with individuals to check their knowledge about investment and saving behavior and attitudes. Dash (2010) analyzed the factors that influence investment decision and differences in the perception of investors in the decision of investing on the basis of Age and Gender. The data was collected through questionnaire from the target group whom age was more than 22 year. It was analyzed that investors considered security as the most important criterion before making any investment and wanted to take suggestions from peers, financial experts or any share brokers. Further, it was concluded that investors age and gender predominantly decides the risk taking capacity of investors. Jain and Mandot (2012) explored the impact of demographic factors on investors investment decisions and also the relationship between demographic factors and the level of risk taking ability of investors in Rajasthan. It was resulted that various demographic factors like age, marital status, gender, city, income level, market knowledge, occupations and qualification etc. have major impacts on investment decision of investors while gender and city have no impact on their investment decisions. Sellappan et al. (2013) identified the factors influencing women investor's behavior to evaluate the level of awareness among women investors and to analyze the preference of women investor towards various investment outlets with special reference to Erode district. It was found that there were certain age and marital differences occurred in the behavior of selecting the investment sources. Younger and unmarried women were usually risk takers. While older and married were risk averse. The study would be helpful to the government and non-governmental organizations to launch various saving schemes for women that in return would promote the economic development of the country.

\section{Objective of the Study}

All the studies reviewed above highlight one aspect i.e. not many studies have been conducted to study the factors influencing the investment attitude of women especially employed in the education sector in India. So, specifically the main objective of the present study is to explore the factors influencing the investment attitude of women employed in the education sector in Punjab.

\section{Data Base and Research Methodology}

For the present study, primary survey has been conducted with the help of a structured questionnaire. The questionnaire was developed after a thorough review of studies on various aspects of investment behaviour of respondents. The 32-item scale was constructed to collect data regarding the factors influencing the investment attitude of women working in education sector. The sample size for the study is 214 respondents. The data has been analysed by using factor analysis. SPSS Software (Version 16.0) has been used for analysis of the collected data.

\section{Analysis and Findings}

In order to achieve the objective of the study a set of 32 statements (Appendix 1) was formulated on the basis of review of literature to determine the factors influencing the investment attitude of women working in education sector. The respondents were asked to rate the statements/ variables on a five point likert scale ranging from 'Strongly Agree' to 'Strongly Disagree' (Whereby Strongly agree $(\mathrm{SA})=5, \operatorname{Agree}(\mathrm{A})=4, \operatorname{Neutral}(\mathrm{N})=3$, Disagree $(\mathrm{D})=$ 2 and Strongly disagree $(\mathrm{SD})=1)$.

For the present study, the overall Cronbach's alpha for the 32-item scale has been estimated as 0.779, which indicates an adequate level of internal consistency. The 32item scale also insures the content validity as it has been prepared on the basis of review of literature.

Before applying factor analysis the data was examined with the help of Correlation Matrix, Kaiser-Meyer-Olkin (KMO) and Bartlett's test of Sphericity. The results are as follows:

- Correlation: Correlation matrix provides the valuable insights by defining the appropriateness of factor analysis. If the correlations between all the variables are high, factor analysis will be appropriate (Malhotra, 2012). The 32-item scale exhibited enough correlation among all the variables indicating the appropriateness of factor analysis.

- Kaiser-Meyer-Olkin Measure of Sampling Adequacy: KMO is another useful statistic which is used to examine the appropriateness of factor analysis. "High values (between 0.5 and 1.0) indicate factor analysis is appropriate. Values below 0.5 imply that factor analysis may not be appropriate" (Malhotra, 2012). For the present study 32-item scale, the value of KMO is 0.702 (as shown in Table 1) which is between 0.5 to 1.0 thereby indicating that data is fit for applying factor analysis.

- Bartlett's Test of Sphericity: “The Bartlett's test of sphericity, a statistical test for the presence of correlations among the variables, is one such measure. It provides the statistical significance that the correlation matrix has significant correlations among at least some of the variables" (Hair et al., 2015). Table 1 shows the value of Chi-Square $=2.8313, \mathrm{df}$ 
$=496$ and $\mathrm{p}$ value $=0.000$ which further depicts the appropriateness of data for applying factor analysis.

Hence, all the above measures show that data is fit for applying factor analysis.

Table 1: Kmo and Bartlett's test

\begin{tabular}{|l|l|c|}
\hline $\begin{array}{l}\text { Kaiser-Meyer-Olkin } \\
\text { Sampling Adequacy }\end{array}$ & Measure of & 0.702 \\
\hline $\begin{array}{l}\text { Bartlett's Test of } \\
\text { Sphericity }\end{array}$ & $\begin{array}{l}\text { Approx. } \\
\text { Chi-Square }\end{array}$ & 2.8313 \\
\cline { 2 - 3 } & Df & 496 \\
\cline { 2 - 3 } & Sig. & 0.000 \\
\hline
\end{tabular}

Source: Survey Data

After examining the appropriateness of data for factor analysis, Principal Component Analysis was used to determine the factors influencing the investment behaviour of women working in education sector of Punjab. Out of total 32 variables four variables namely; V4, V10, V11 and V12 were negative in nature. So while conducting factor analysis, reverse coding was done for analyzing these statements.

The items that had loading of 0.45 or greater and were clearly loaded on only one factor were retained for factor analysis.
Table 2: Guidelines for indentifying significant factor loadings based on sample size

\begin{tabular}{|c|c|}
\hline Factor Loading & $\begin{array}{c}\text { Sample Size Needed } \\
\text { for Significance }\end{array}$ \\
\hline 0.30 & 350 \\
\hline 0.35 & 250 \\
\hline 0.40 & 200 \\
\hline 0.45 & 150 \\
\hline 0.50 & 120 \\
\hline 0.55 & 100 \\
\hline 0.60 & 85 \\
\hline 0.65 & 70 \\
\hline 0.70 & 60 \\
\hline 0.75 & 50 \\
\hline
\end{tabular}

Source: Hair et al., (2015)

Table 2 shows the guidelines for indentifying significant factor loadings based on sample size. The sample size for the present study is 214 respondents. So as per above guidelines factor loading of 0.45 or above has been considered.

Table 3: Rotated factor matrix

\begin{tabular}{|c|c|c|c|c|c|c|c|c|}
\hline Variables & F1 & $\mathbf{F} 2$ & F3 & F4 & F5 & F6 & F7 & Communalities \% (h2) \\
\hline V1 & -0.011 & 0.142 & 0.028 & 0.090 & 0.055 & 0.111 & 0.723 & 0.567 \\
\hline $\mathrm{V} 2$ & 0.124 & 0.394 & -0.006 & -0.030 & 0.152 & -0.226 & 0.541 & 0.538 \\
\hline V3 & 0.169 & 0.469 & 0.142 & 0.084 & 0.115 & -0.159 & 0.273 & 0.389 \\
\hline $\mathrm{V}_{4}$ & 0.383 & 0.034 & -0.018 & 0.147 & 0.158 & -0.458 & 0.345 & 0.524 \\
\hline V5 & 0.146 & 0.607 & 0.132 & 0.166 & 0.044 & -0.275 & 0.297 & 0.600 \\
\hline V6 & 0.196 & 0.720 & 0.074 & -0.081 & -0.125 & 0.146 & 0.039 & 0.607 \\
\hline V7 & -0.094 & 0.641 & -0.042 & 0.068 & 0.012 & 0.345 & -0.072 & 0.550 \\
\hline V8 & -0.087 & 0.699 & 0.080 & 0.078 & -0.019 & 0.010 & 0.133 & 0.527 \\
\hline V9 & 0.235 & 0.376 & 0.557 & 0.323 & -0.087 & -0.030 & -0.061 & 0.624 \\
\hline V10 & 0.654 & -0.121 & -0.004 & 0.259 & -0.118 & -0.202 & 0.084 & 0.571 \\
\hline V11 & 0.660 & 0.047 & -0.014 & 0.372 & -0.060 & -0.114 & -0.068 & 0.598 \\
\hline V12 & 0.383 & -0.142 & 0.176 & 0.355 & 0.110 & 0.148 & -0.275 & 0.434 \\
\hline V13 & 0.165 & 0.051 & 0.056 & 0.405 & 0.539 & -0.351 & 0.147 & 0.632 \\
\hline V14 & 0.032 & 0.072 & 0.167 & 0.352 & 0.585 & -0.193 & 0.017 & 0.537 \\
\hline V15 & 0.014 & 0.112 & -0.173 & 0.763 & 0.061 & -0.089 & 0.138 & 0.655 \\
\hline V16 & -0.034 & 0.107 & -0.164 & 0.751 & 0.116 & -0.022 & 0.044 & 0.620 \\
\hline V17 & 0.184 & 0.348 & -0.542 & 0.280 & 0.335 & -0.138 & -0.080 & 0.664 \\
\hline V18 & 0.068 & 0.368 & -0.580 & 0.376 & 0.237 & -0.064 & -0.053 & 0.681 \\
\hline V 19 & -0.106 & 0.242 & 0.392 & -0.325 & 0.482 & 0.098 & -0.285 & 0.652 \\
\hline V20 & -0.091 & 0.191 & 0.438 & -0.248 & 0.468 & 0.025 & -0.401 & 0.679 \\
\hline $\mathrm{V} 21$ & 0.040 & -0.040 & 0.071 & -0.087 & 0.626 & 0.274 & 0.200 & 0.523 \\
\hline V22 & 0.127 & -0.151 & -0.025 & 0.149 & 0.677 & 0.159 & 0.021 & 0.545 \\
\hline
\end{tabular}




\begin{tabular}{|c|c|c|c|c|c|c|c|c|}
\hline V23 & -0.085 & 0.212 & 0.672 & -0.109 & 0.246 & 0.096 & 0.129 & 0.602 \\
\hline V24 & -0.101 & 0.045 & 0.629 & -0.102 & 0.211 & 0.100 & -0.095 & 0.482 \\
\hline V25 & 0.690 & 0.120 & 0.024 & -0.246 & 0.092 & -0.049 & -0.074 & 0.568 \\
\hline V26 & 0.749 & 0.149 & 0.008 & -0.054 & 0.065 & -0.006 & 0.020 & 0.591 \\
\hline V27 & 0.630 & 0.050 & -0.248 & -0.103 & 0.137 & -0.222 & 0.296 & 0.627 \\
\hline $\mathrm{V} 28$ & 0.578 & 0.044 & -0.314 & 0.028 & 0.144 & -0.180 & 0.291 & 0.574 \\
\hline V29 & -0.019 & 0.285 & 0.526 & -0.036 & 0.188 & 0.403 & 0.133 & 0.575 \\
\hline V30 & -0.145 & 0.066 & 0.178 & -0.009 & 0.142 & 0.759 & 0.028 & 0.654 \\
\hline V31 & -0.191 & 0.006 & 0.164 & -0.102 & 0.074 & 0.776 & 0.017 & 0.682 \\
\hline V32 & 0.222 & 0.289 & 0.382 & 0.092 & -0.079 & 0.305 & 0.428 & 0.570 \\
\hline Eigenvalues & 5.310 & 4.273 & 2.349 & 2.276 & 1.527 & 1.474 & 1.435 & \\
\hline $\begin{array}{c}\% \text { of } \\
\text { Variance }\end{array}$ & 10.965 & 9.894 & 9.792 & 7.975 & 7.860 & 7.996 & 6.693 & \\
\hline $\begin{array}{c}\text { Cumulative } \\
\%\end{array}$ & 10.965 & 20.859 & 30.651 & 38.626 & 46.486 & 54.482 & 61.175 & \\
\hline
\end{tabular}

Source: Calculated through SPSS

The factor analysis (Table 3) resulted in the extraction of 7 factors which accounted for 61.175 per cent of the variance which is above the recommended level. "It is recommended that the factors extracted should account for at least 60 percent of the variance" (Malhotra, 2012). The table 3 also shows that variables namely; V12 and V32 were not loaded on any factor. Hence, the two variables were not considered for factor analytic results.

\section{F1: Secure Investment Avenues}

Secure investment avenues is the first and most important factor which comprises of six variables. This factor explains 10.965 per cent of the total variance of the data with an eigen value of 5.310. It reveals that women investors preferred to invest their funds in provident funds and insurance schemes as compared to other riskier avenues.

\section{F2: Financial Literacy}

The second factor "Financial Literacy" explains 9.894 per cent of the total variance of the data with an eigen value of 4.273. This factor encompasses five variables. As regards the effect of financial literacy on the economic development of women the results of this factor are in consonance with the findings of Ashwinprabha and Pandian (2016), Sharma and Joshi (2015) and Haque and Zulfiqar (2016) respectively.

\section{F3: Stock Market Investment and Post Office Schemes}

The third important factor is "Stock Market Investment and Post Office Schemes" which accounts for 9.792 per cent of the total variance with an eigen value of 2.349 . It comprises of six variables. This factor shows that the respondents prefer more to invest in mutual funds as compare to post office schemes.

\section{F4: Bank Deposits}

The fourth factor "Bank Deposits" explains 7.975 per cent of the total variance in the data with an eigen value of 2.276. It encompasses only two variables. The preference for saving deposits in bank were also discussed by Achar (2012), Agarwal et al. (2015) and Parimalakanthi and Kumar (2015) in their respective studies.

\section{F5: Physical Assets}

The fifth factor "Physical Assets" comprises of six variables that accounts for 7.860 per cent of the total variance with an eigen value of 1.527. Six factors are included in this factor that explains the women investors preference to invest in real estate and gold.

\section{F6: Risk Taking Ability}

The sixth factor "Risk Taking Ability" is a combination of three variables and explains 7.996 per cent of the total variance in the data with an eigen value of 1.474 . This factor shows the risk taking ability of women investors in comparison of negligible return, low return and moderate return.

\section{F7: Concern for Financial Matters}

The seventh factor "Concern for Financial Matters" comprises of two variables. This factor explains 6.693 per cent of the total variance in the data with an eigen value of 1.435 . It reveals that women investors are very concerned about financial matters and like investing their funds.

\section{Conclusion and Suggestions}

Women have greater tendency towards risk aversion and is one of the reason that they look for more safe and steady return investment patterns. Percentage of income 
that they invest depends on their annual income. The study resulted that higher the income more percentage of their income that they invest. Factor Analytical results revealed that women investors prefer to invest in risk free securities. The level of financial knowledge also influences their investment attitude. The present study reveals the factors namely; secure investment avenues, financial literacy, stock market investment and post office schemes, bank deposits, physical assets, risk taking ability and concern for financial matters that are important to women working in education sector. So in future the researchers can use this study for further analysis.

\section{References}

Arora, A. (2016). Assessment of Financial Literacy Among Working Indian Women. Business Analyst, 36(2), 219-237.

Achar, A. (2012). Saving and Investment Behaviour of TeachersAn Empirical Study. International Journal of Physical and Social Sciences, 2(8), pp. 263-286.

Agarwal, P., Ansari, S., Yadav, S and Kureel, R. (2015). A study on financial literacy among working women in educational sector of Jhansi District: with special reference to investment avenue. International Journal of Advance Research in Science and Engineering, 4(1), pp. 54-61. https://doi.org/10.9790/487X-2005051924

Ashwinprabha, V. and Pandian, M. P. (2016). Interrelationship between investment behavior and financial literacy: A study with specific reference to married women in Pollachi Taluk. International Journal of advance research in computer science and management studies, 4(6).

Bernasek, A. and Bajtelsmit, V. (2002). Predictors of Women's Involvement in Household Financial Decision Making. Financial Counseling and Planning, 13(2), pp. 39-47.

Kabra, G., Mishra, P. K. and Dash, M. (2010). Factors influencing investment decision of generation in India: An Econometric Study. Indian Institute of Information Technology and Management, 1(1).

Hair, J. R, Joseph F., Black, William C., Babin, Barry J., and Anderson, Rolph E (2015). Multivariate Data Analysis. ( $7^{\text {th }}$ ed.) Harlow, England: Pearson/Prentice Hall.

Haque, A. and Zulfiqar, M. (2016). Women's Economic empowerment through Financial Literacy, Financial Attitude and Financial Wellbeing. International Journal of Business and Social Science, 7(3), pp. 78-88.

Jain and Mando, N. (2012). Impact of Demographic factors on Investment Decision of Investors in Rajasthan. Journal of Arts, Science and Commerce, 3(2(3)).

Janice and Dwyer, M. (2007). Households attitudes to Saving, Investment and Wealth. Reserve Bank of New Zealand: Bulletin, 70(4).

Joshi, B. and Sharma, A. (2015). Financial Literacy of Women and its Effect on their Investment Choice Decision. Global Journal For Research Analysis, 4(7).

Kumar, A. and Parimalakanthi. K. (2015). A study of investment preference and behavior of individual investors in Coimbatore city. Bonfring International Journal of Industrial Engineering and Management Science, 5(4), pp. 170-174. https://doi.org/10.9756/BIJIEMS.8122
Kousalya, P. R. and Gurusamy, P. (2012). Women Investors Perception Towards Investments. International Journal of Scientific Research, 1(6), pp. 80-81.

Lad, T. T. (2015). Analytical Study on Financial Planning \& Behavior of Working Women Towards Investment Products in Devgad Tehsil. Doctoral Thesis, Shri Jagdishprasad Jhabarmal Tibrewala University, Rajasthan, India.

Malhotra, N. K., and Dash, S. (2012). Marketing Research: An Applied Orientation (6 $6^{\text {th }}$ ed.). Dorling Kindersley, India: Pearson/Prentice Hall.

Mishra, B. and Kar, N. C. (2004). A Study of the Perception and Behavior Related Issues in Investment Decisionmaking process by Employed Women. Utkal University, Bhubaneshwar (Doctoral Dissertation).

Sellappan, J. and Tnri, K. (2013). Investment Attitude of Women towards different Sources of Securities- A Factor Analysis Approach. Global Journal of Management and Business Research Finance, 13(3), pp. 27-30.

Soni, M. and Deshmukh, J. (2015). Achievement motivation as related to parental involvement of secondary school students. Scholarly research journal for humanity science and English language, 2(9). 


\section{Appendix 1}

List of variables influencing the investment behaviour of working women

\begin{tabular}{|c|c|}
\hline Variable & Description \\
\hline V1 & I am very concerned about financial matters. \\
\hline V2 & I like investing and actively look forward towards it. \\
\hline V3 & I compare and calculate risks before investing. \\
\hline V4 & After making a decision, I become nervous whether I was right or wrong. \\
\hline V5 & To make money, I am prepared to take substantial risks. \\
\hline V6 & I feel that I have good knowledge about financial markets and can track my investments. \\
\hline $\mathrm{V7}$ & I feel more reliable with the information that I collect by myself. \\
\hline V8 & I frequently check the performance of my investments. \\
\hline V9 & Though equity investment is not a fun, it is worth investing for me. \\
\hline V10 & I lack sufficient technical knowledge which is needed to make stock market investments. \\
\hline V11 & The complex procedure and formalities of stock market restricts me from making investment. \\
\hline V12 & Stock market investment is difficult for me due to family restrictions. \\
\hline V13 & I would like to invest my savings in gold. \\
\hline V14 & Gold gives us good return. \\
\hline V15 & I would like to keep my money in savings deposits of bank. \\
\hline V16 & Savings deposit in bank is a risk free investment. \\
\hline V17 & I would like to keep my money in post-office. \\
\hline V18 & Post-office scheme investment is a risk free investment. \\
\hline V19 & I would like to invest my savings in Corporate Bonds. \\
\hline V20 & Corporate Bonds are risk free investment. \\
\hline V21 & I would like to invest my savings in Real Estate. \\
\hline V22 & Investment in Real Estate has no risk. \\
\hline V23 & I would like to invest in Mutual fund schemes. \\
\hline V24 & Mutual fund is a risk free investment avenue. \\
\hline V25 & I would like to invest my savings in Insurance schemes. \\
\hline V26 & Insurance schemes have no risk. \\
\hline V27 & I would like to invest in Provident fund. \\
\hline V28 & Provident fund is a risk free investment. \\
\hline V29 & $\begin{array}{l}\text { I would like to invest in an avenue which gives me very good return even if it is very risky to } \\
\text { invest in it. }\end{array}$ \\
\hline V30 & I would like to invest in an avenue which has low risk even if it gives me low return. \\
\hline V31 & I would like to invest in an avenue which has no risk even if it gives me negligible return. \\
\hline V32 & $\begin{array}{l}\text { I would like to invest in a combination of avenues of high risk and low risk for a medium } \\
\text { return. }\end{array}$ \\
\hline
\end{tabular}

Source: Review of Literature 


\section{Journal of Technology Management for Growing Economies \\ Chitkara University, Saraswati Kendra, SCO 160-161, Sector 9-C, CHIKARA Chandigarh, 160009, India}

Volume -10, Issue-2

October 2019

ISSN 2456-3226

Copyright: [C 2019 Poonam Sharma et. al.] This is an Open Access article published in Journal of Technology Management for Growing Economies by Chitkara University Publications. It is published with a Creative Commons Attribution- CC-BY 4.0 International License. This license permits unrestricted use, distribution, and reproduction in any medium, provided the original author and source are credited. 